\title{
Prevalence of stunting and associated factors among preschool children: A community based comparative cross sectional study in Ethiopia
}

\author{
Getnet Berhanu', Solomon Mekonnen² and Mekonnen Sisay ${ }^{2 *}$
}

\begin{abstract}
Background: The prevalence of under nutrition is very high in developing countries especially in women and under five children. Stunting alone affected an estimated 154.8 million (22.9\%) under five children globally in 2016. It is one of the main undernutrition and health problems facing children in Ethiopia. Hence, the aim of the current study was to assess the prevalence and associated factors of stunting among preschool children from food secure and food insecure households in Albuko district, northeast Ethiopia.

Methods: This study was addressed by a community based comparative cross sectional study design which was conducted among preschool children in Albuko district from March to April 2017. Simple random sampling was used to select the five representative kebeles. To reach study participants, systematic sampling technique was utilized. Pretested and structured questionnaire was used to collect data. Height measurement was collected for each child. Anthropometric indicator, height-for-age was determined for children using current WHO growth standards. Adjusted odds ratio (AOR) with its $95 \%$ confidence interval (CI) was computed to assess the strength of the association. To identify the associated factors of stunting, multivariable logistic regression models were built. In the multivariable analysis, variables with a P-value of $<0.05$ were considered statistically significant.

Results: The overall combined prevalence of stunting among preschool children in the study area was 39.3\% [95\%Cl; 36.3, 42.3\%]. A higher stunting prevalence was observed among preschool children from food insecure households [42.8\%, 95\%Cl; 38.4, 47.2\%] than food secure ones [35.9\%, 95\%Cl; 31.7, 40.1\%]. Having uneducated mothers, large family size, and male sex were common factors significantly associated with stunting in both food secure and insecure households. While child birth order and the amount of water ( $<40$ litters) for use were significantly associated with stunting among preschool children living in food secure households, and lesser child age, lack of extra food during pregnancy/lactation, and low dietary diversity score (DDS below four food groups) were significantly associated with stunting among preschool children from food insecure households.

(Continued on next page)
\end{abstract}

\footnotetext{
* Correspondence: mekudesu@gmail.com

${ }^{2}$ Department of Human Nutrition, Institute of Public Health, College of

Medicine and Health Sciences, University of Gondar, Gondar, Ethiopia

Full list of author information is available at the end of the article
}

(c) The Author(s). 2018 Open Access This article is distributed under the terms of the Creative Commons Attribution 4.0 International License (http://creativecommons.org/licenses/by/4.0/), which permits unrestricted use, distribution, and reproduction in any medium, provided you give appropriate credit to the original author(s) and the source, provide a link to the Creative Commons license, and indicate if changes were made. The Creative Commons Public Domain Dedication waiver (http://creativecommons.org/publicdomain/zero/1.0/) applies to the data made available in this article, unless otherwise stated. 


\begin{abstract}
(Continued from previous page)
Conclusion: The present study showed that stunting is an important public health problem among preschool children from both food secure and insecure households in Albuko district. Though productive safety net program (PSNP) is a proven strategy in reducing the burden of childhood undernutrition/stunting, this study showed that there is no significant variation in the magnitude of stunting. However, it does not mean that PSNP interventions are not important in reducing the prevalence of stunting. Therefore, strengthening maternal nutrition, family planning utilization, and maternal education and enhancing dietary diversity, water sanitation and hygiene are critical interventions to reduce the level of stunting among under five children.
\end{abstract}

Keywords: Stunting, preschool, children, associated factors, Ethiopia

\section{Background}

Child mortality in developing countries are mostly due to preventable causes. More than 50 percent of deaths among children below five years old were contributed by malnutrition alone in third world countries [1,2]. Stunting affected an estimated $22.9 \%$ or 154.8 million under five children globally in 2016 and the two continents; Asia and Africa are the home to most children who are stunted and each of them contributed 87 million and 59 million to the burden of stunting among children in the globe respectively [3]. In Africa, one in three children is stunted, and the prevalence (around 40\%) to which 14 countries including Ethiopia are home to $80 \%$ of stunting among children in the world and contribute $3 \%$ of stunting burden globally has remained unchanged in the past twenty years $[4,5]$.

In Ethiopia, undernutrition remains a serious challenge. As a result, 45 percent of Ethiopian children deaths were associated with undernutrition where its causes are multifaceted [6]. According to Ethiopian Demographic and Health Survey 2016 (EDHS 2016) report, compare to the previous survey report the number of stunted children under five years old showed a decreasing pattern over the last five years from $44 \%$ in 2011 to 38\% in 2016 but, still 38\% of Ethiopian under five children are suffering from stunting of them $18 \%$ are severely stunted $[7,8]$.

Child undernutrition has long-term negative consequences. A child who is undernourished will have repeated episodes of infection, less competent in his education and lower productivity than well-nourished child [9]. And again, a child who is stunted have poor physical growth, cognitive development and low school performance $[10,11]$. In addition, the loss in human and economic potential is significant and currently in Ethiopia, undernutrition is responsible for 25 percent of child deaths [12]. According to the cost of hunger analysis in Ethiopia for 2009, Ethiopia has lost 16.5\% of her GDP (4.7 billion \$US) of 2009 due to undernutrition [12].

As outlined by UNICEF a child from food insecure household will be malnourished [13]. Food security is defined as "Food security exists when all people, at all times, have physical and economic access to sufficient, safe, and nutritious food that meets their dietary needs and food preferences for an active and healthy life" [14]. Being secured in food does not mean that there is an adequate nutrition [15]. It is one of the pillars of improving nutrition status, but doesn't necessarily mean that children from food secure households are well nourished. Malnutrition is common in many food secure households $[16,17]$. A pooled analysis involving children aged 1 week to 59 months in 10 prospective studies in Africa, Asia, and South America (anthropometry cohort pooling) by Ibironke Olofin et al in 2013 showed that infection leads to undernutrition, and all degrees of anthropometric deficits increased the hazards of dying from respiratory tract infections and diarrheal diseases [18].

The causes of undernutrition are multifaceted. Inadequate dietary intake and disease, household food insecurity, poor caring practices, lack of access to basic services, including lack of access to safe water supply, health services (including knowledge and training of health workers); and unhealthy living environment, such as open defecation [19]. In turn, these causes are influenced by 'economic, political and social conditions, national and global contexts, capacity, resources, environmental conditions and governance' [6].

International and national commitments to eliminate malnutrition (especially stunting) has increased in recent years. Countries have made commitments through the sustainable development goals (SDGs) [20], the United Nations Decade of Action on Nutrition (2016-2025) [21], Malabo Declaration [22] and the Scaling Up Nutrition Movement (SUN) [23], to address malnutrition especially with focus on stunting reduction in children under five years. Similarly, World Health Assembly (WHA) targeted to reduce $40 \%$ of global stunting by 2025 [24].

Ethiopia also set stunting reduction as one goal of the Growth and Transformation Plan (GTP) with national nutrition strategies, different nutrition specific and nutrition sensitive intervention activities with focus on improving Infant and Young Child Feeding (IYCF), management of severe acute malnutrition and prevention and treatment 
of micronutrient deficiencies [6, 25, 26]. The Government of Ethiopia developed the Productive Safety Net Program (PSNP) in 2004 to target chronically food insecure households aimed at enabling the rural poor facing chronic food insecurity to resist shocks, create assets, and become food self-sufficient [27, 28]. PSNP user families are experiencing improved food security, community level infrastructure development, increase asset creation and protection, increase utilization of education and health services with positive short term nutritional benefit for children [29, 30].

However, stunting across preschool children is not assessed well, particularly in relation to household food security status. Therefore, the aim of this study was to determine the prevalence of stunting and its associated factors in a study population of children from food secure and food insecure households.

\section{Methods}

\section{Study setting}

The study was conducted in Albuko district, northeast Ethiopia. The district consists of 16 kebeles (the smallest administrative units in Ethiopia) of which 13 are rural. It has a total population of 88,954 of which 47,613 (53.5\%) were male and 41,340 (46.5\%) female. Children aged 24 to 59 months comprised 7,552 (8.5\%) of the total [31]. According to the district early warning and response cluster report 2016, out of the total 20,483 households, $45 \%$ of them were Productive Safety Net Program (PSNP) beneficiaries [32].

There are 4 health centers and 16 health posts in the district. Albuko district is one of the districts of the Amhara region, where the routine community based nutrition intervention program is being implemented with due collaboration with Save the Children and Concern Worldwide Ethiopia [31].

Albuko is one of the most food insecure district in Amhara region. Seasonal variation of rainfall and infertile land are the main contributing factors to food insecurity. According to the 2016 district report, there were 20,483 households of which 11,183 (55\%) were food secure, whereas the rest, 9,300 (45\%) households (HHs) were food insecure ones. Both chronically and acutely food insecure HHs were enrolled in the PSNP. Accordingly, $95 \%$ of the $\mathrm{HHs}$ were chronically food insecure and $5 \%$ were acutely food insecure. The PSNP has two delivery modalities, the cash which was given to households with able bodied members who can repay it by engaging in any developmental activities, like water and soil conservation, road construction, etc. and was given to $85 \%$ of the HHs. On the other hand, the food aid was given to households with no able-bodied members and was given to $15 \%$ of the $\mathrm{HHs}$ [33].

\section{Study design and participants}

A community-based comparative cross-sectional study was conducted from March to April 2017, to determine the level of stunting and tis associated factors. All preschool children aged 24-59 months who had lived at least for six months in the selected HHs were included.

\section{Sample size determination and sampling procedure}

As it was a comparative cross-sectional study, the minimum sample size was determined by using the double population proportion formula with the following assumptions that two groups were considered based on their PSNP beneficiary status. Group one was with PSNP as exposed (as food insecure HHs) and group two was without PSNP as not exposed (food secure HHs). To estimate the minimum sample size of the study a stunting prevalence of $37.5 \%$ was used from the findings of a previous study in East Gojjam Zone among food secured households and in food surplus areas [34] and a 50\% prevalence of stunting among food insecure households (since there were no previous specific studies conducted among food insecure households or areas at least to the time of the proposal stage of this work) were used. Then, the sample size estimation was calculated using Epi Info software and with a $95 \%$ confidence level and a 5\% margin of error yielded 496. Considering non-response rate of $10 \%$ and a design effect of 2 for both comparative groups, a minimum sample size of 1090 was obtained.

Both multi-stage and systematic sampling techniques were used to include respondents with their preschool children. In the first step, five among 16 kebeles were selected by simple random sampling method. In the second step, sampling fraction $(\mathrm{k})$ was calculated using the total number of children available in the kebeles. Households in the selected five Kebeles were stratified according to their PSNP status. Finally, after allocation proportional to population size of each kebele, the households were selected by systematic random sampling technique. Children's ccaretakers or mothers in the selected households were interviewed and measurements of anthropometric data (height and age) were taken. As five households (5 mother-child pairs) could not be traced even after two more/repeated visits, their five adjacent counterparts were considered.

\section{Data collection tools and procedure}

Quantitative data collection techniques/instruments were employed to gather the necessary information. A structured questionnaire composed of socio-demographic characteristics, maternal and child health characteristics, vitamin A, deworming supplementations, feeding practices of children and water hygiene and sanitation information were used to collect the data. Initially, the questionnaire was prepared in English language. Then it was translated to the local 
language Amharic. The daily data collection was closely supervised by the principal investigator. The questionnaire was pretested on $5 \%$ of the total samples outside the study area. During the pretest, acceptability and applicability of procedures and tools were evaluated. Six diploma graduate clinical nurses recruited as data collectors supervised by three-degree graduate clinical nurses after three days' training given to both groups. During home visits, if the caregiver was absent, a second visit was made.

\section{Anthropometric measurements}

Height was measured using the standardized vertical seca 213 portable stadiometer measurement.

Thick socks, shoes, and jackets or any bulky clothing of a child were removed. A child has stood with his/her back against the measuring surface with feet together flat on the floor, arms at side and knees and back straight. Head, heels, buttocks and shoulder blades of a child were touched the measuring surface. A child was looking straight ahead, then the headboard was slid gently down to the head of the child, compressing the hair. When measurer's eyes level with the indicator, the height of the child was read to the nearest 0.1 centimetre. Then, the procedure was repeated for the second time completely. Comparison was made between the two measurements. Accordingly, if the difference between the two measurement readings were within 0.1 centimetre, the second measurement was recorded. Otherwise the average of the two measurements were taken.

When documents such as vaccination cards were available, they were used to determine the age of the children. In the absence of documentation, a local seasonal calendar method was used by the team as they were trained on how to assess age of the children. In this regard, for 941 (90.6\%) children the exact age was found from the immunization card registry (family folder), for the rest, 98 (9.4\%), age was approximated. Anthropometric related data of a child were transferred to the ENA/ SMART software version 2012 and the Z-score of index, Height-for-Age Z-score (HAZ), was calculated using the WHO Multicenter Growth Reference Standard. The child was classified as stunted if his/her $\mathrm{z}$ score was less than $-2 \mathrm{SD}$ and not stunted if $\mathrm{Z}$ score was $\geq-2 \mathrm{SD}$ [35].

\section{Assessment of dietary diversity}

The dietary diversity of children was assessed whether they had eaten the different food groups from yesterday's sun rise to today's sun rise (24hours recall method) prior to the survey date according to their mothers or caregiver's responses. Then based on reports of their mothers or caregivers, food items consumed by the children were grouped in to seven food groups. The seven food groups were starchy staples (grains, roots, and tubers), legumes, nuts and seeds, vitamin-A rich fruits and vegetables, other fruits and vegetables, egg, dairy products (milk, yoghurt, and cheese); and flesh foods (meat, fish, poultry, and organ meats). Finally, dietary diversity score of children was calculated out of the seven food groups. A child with a DDS of four and above was classified as having good dietary diversity, otherwise classified as poor [36].

\section{Data quality assurance}

The maximum efforts were made to maintain data quality. During the development of data collection tool, all authors reviewed the data collection instruments and the pretest was performed in similar communities before using it for the actual data collection. Careful selection and recruitment of experienced data collectors and supervisors were employed. Training was conducted for three days on survey objectives, survey methodology, measurement, and recording of anthropometric measurements (height and age), basic nutrition index, and its use. Theoretical sessions and practical demonstrations on children's height measurement, age estimation, and collection of other nutrition related information was provided on the first two days. The third day was spared for pretesting of the questionnaire and the methodology. This consisted of field practice, including height measurement and age estimation exercise in a nearby village that had not been selected for the actual study. During the three days training, interview ethics and techniques were included in order to improve the quality of data. For pretesting, all data collectors and supervisors were participated. In addition, a strong daily field supervision was carried out to monitor the performance of data collectors and to deliver on the spot correction/feedback on any mistakes noted and to facilitate supervisor reviews of the questionnaire to ensure its completeness before the household was left.

\section{Data Processing and Analysis}

The collected data were coded, cleaned and entered into Epi data version 3.1 and exported to Statistical Package for Social Science (SPSS) version 20 software for analysis. The WHO Anthro software was used to enter and determine the prevalence of stunting among preschool children aged 24-59 months. Height and age data were used to calculate height-for-age $\mathrm{z}$ score and to categorize the severity level of stunting based on the World Health Organization's Anthro reference. Stunting is defined as low height-for-age at less than $-2 \mathrm{SD}$ and severe at less than $-3 \mathrm{SD}$ of the median value of the WHO international growth reference [35]. Prior to data analysis, missing values were checked and corrected by referring to the original data filled in the questionnaire. Descriptive statistics were used to summarize study variables. In addition, tables and figures were used to summarize the 
frequencies and proportions of the variables. Three models were run to identify factors associated with stunting among preschool children from food secure, and insecure households; the final model was run to identify the contributing factors to stunting among the total preschool children in the study sample. The association between stunting and the independent categorical variables was investigated by using the logistic regression model (bivariable analysis). A $p$ value of $<0.2$ in the bivariable analysis were considered as a variable selection criterion. Accordingly, all variables which were significant at $\mathrm{A} \mathrm{p}$ value of $<0.2$ were entered into the multivariable analysis in order to control the possible effects of confounders. In multivariable analysis, backward selection method was used to identify factors associated with stunting and statistical significance was considered with a $\mathrm{p}$ value of $<0.05$. The adjusted odds ratio (AOR) with a $95 \%$ confidence interval was used to assess the strength of association. Furthermore, the fitness of the logistic regression model was checked using the Hosmer and Lemeshow goodness of fit-test, and found a $\mathrm{p}$ value of $>0.05$ for the three models fitted separately.

\section{Ethical consideration}

Before data collection, ethical clearance was collected from the University of Gondar Institutional Ethical Review Board. The Zonal health department and the Albuko district health office gave us permission to proceed with the data collection. After informing about the whole purpose, the benefits, the risks, the confidentiality of information, and the voluntary nature of participation in the study, oral informed consent and thumb print were obtained from each participant (mother or caregiver). Names of the respondents were not recorded. Data were accessed only by the investigator to ensure confidentiality. Respondents were informed that they had the right to refuse or stop at any point of the interview. Children with nutritional and health problems were counseled and linked to cluster health facilities.

\section{Results}

\section{Socio-demographic characteristics}

The present study included 1073 preschool children. Out of these $3.1 \%$ preschool children HAZ index were flagged and excluded from the study. One thousand thirty-nine (1039) children were included for the final analysis. Respondents from food secure and food insecure households comprised $50.7 \%$ and $49.3 \%$, respectively.

The mean age $( \pm S D)$ of preschool children from food secure and food insecure households were 40.78 \pm 10.37 and $41.01 \pm 10.39$ months. More than half (55.6\%) of them were females. More than half (57.9\%) of female preschool children were from food secure households and $53.3 \%$ female preschool children were from food insecure households. The majority of the respondents (90.8\%) were housewives and slightly more than half of them (53.5) had more than four family members (Table 1).

\section{Maternal and child health characteristics}

The majority $(90.5 \%)$ and $(88.3 \%)$ of the mothers had at least one Antenatal Care (ANC) visit for the index child from food secure and food insecure households and around $65.5 \%$ and $59.2 \%$ of them gave birth at health facilities, respectively. A significant proportion of preschool children (91.5\%) and (90.5\%) from food secure and food insecure $\mathrm{HHs}$ had received vitamin $\mathrm{A}$ and deworming supplementations during the previous six months prior to the data collection period, respectively (Table 2).

\section{Child feeding practices}

Ever breast feed had been practiced by all mothers (100\%) from both food secure and insecure HHs. Nearly hundred percent $(98.5 \%)$ and $(98 \%)$ of the mothers initiated breastfeeding timely, within an hour of delivery, respectively. Less than half (45\%) of them from food secure HHs and slightly more than half (53.3\%) from food insecure had started complementary feeding timely at the 6 month. The minimum dietary diversity and meal frequency score four and more among preschool children were $30.2 \%$ and $66.2 \%$ from food secure $\mathrm{HHs}$, and $24 \%$ and $44.7 \%$ from food insecure ones (Table 3 ).

\section{Water hygiene and Sanitation Characteristics}

The findings showed that $90.5 \%$ of food secure households and $86.1 \%$ of food insecure households source their drinking water from protected sources such as protected spring, pipe, protected well etc. However, 9.5\% and 13.9\% of food secure and food insecure households source their drinking water from unprotected sources such as river, unprotected spring and open wells (Table 4).

\section{Prevalence of stunting}

The overall prevalence of stunting among preschool children was $39.3 \%$ (95\%CI: $36.3 \%-42.3 \%)$, while that of such children from food insecure and food secure households was $42.8 \%$ (95\%CI: 38.4\%-47.2\%) and $35.9 \%$ (95\%CI: $31.7 \%-40.1 \%$ ), respectively. The proportion of severely stunted from food insecure households was $25.2 \%$ and that of food secure was $18.6 \%$. A high proportion of stunting (46.6\%) was observed among male preschool children as opposed to $33.4 \%$ among females in the whole study sample. There was an increasing trend of stunting across age categories among children from food secure households (FSHHs). The highest prevalence of stunting (40.3\%) was observed in the 48-59-month age group and the 
Table 1 Socio-economic and demographic characteristics of the respondents from food secure and food insecure households of Albuko district, northeast Ethiopia, 2017

\begin{tabular}{|c|c|c|c|c|c|c|}
\hline \multirow[t]{2}{*}{ Characteristics } & \multicolumn{2}{|c|}{$\begin{array}{l}\text { Food secure HHs } \\
n=527\end{array}$} & \multicolumn{2}{|c|}{$\begin{array}{l}\text { Food insecure HHs } \\
n=512\end{array}$} & \multicolumn{2}{|l|}{$\begin{array}{l}\text { Total } \\
n=1039\end{array}$} \\
\hline & Frequency & Percent & Frequency & Percent & Frequency & Percent \\
\hline \multicolumn{7}{|l|}{ Ethnicity } \\
\hline Amhara & 505 & 95.8 & 507 & 99.0 & 1012 & 97.4 \\
\hline Others $^{a}$ & 22 & 4.2 & 5 & 1.0 & 27 & 2.6 \\
\hline \multicolumn{7}{|l|}{ Religion } \\
\hline Muslim & 493 & 93.5 & 497 & 97.1 & 990 & 95.3 \\
\hline Orthodox & 34 & 6.5 & 15 & 2.9 & 49 & 4.7 \\
\hline \multicolumn{7}{|l|}{ Marital Status } \\
\hline Single & 32 & 6.1 & 26 & 5.1 & 58 & 5.6 \\
\hline Married & 460 & 87.3 & 479 & 93.6 & 939 & 90.4 \\
\hline Others $^{\mathrm{b}}$ & 35 & 6.6 & 7 & 1.4 & 42 & 4.0 \\
\hline \multicolumn{7}{|l|}{ Under five children } \\
\hline One & 464 & 88.0 & 410 & 80.1 & 874 & 84.1 \\
\hline Two & 58 & 11.0 & 102 & 19.9 & 160 & 15.4 \\
\hline Three & 5 & .9 & 0 & 0 & 5 & .5 \\
\hline \multicolumn{7}{|l|}{ Mother education } \\
\hline Uneducated & 326 & 61.9 & 299 & 58.4 & 625 & 60.2 \\
\hline Primary & 147 & 27.9 & 170 & 33.2 & 317 & 30.5 \\
\hline Secondary and above & 54 & 10.2 & 43 & 8.4 & 97 & 9.3 \\
\hline \multicolumn{7}{|l|}{ Mother occupation } \\
\hline Housewife & 464 & 88.0 & 479 & 93.6 & 943 & 90.8 \\
\hline Government & 17 & 3.2 & 6 & 1.2 & 23 & 2.2 \\
\hline Others ${ }^{c}$ & 46 & 8.7 & 27 & 5.3 & 73 & 7.0 \\
\hline \multicolumn{7}{|l|}{ Money handlers } \\
\hline Husband & 369 & 70.0 & 395 & 77.1 & 764 & 73.5 \\
\hline Wife & 13 & 2.5 & 26 & 5.1 & 39 & 3.8 \\
\hline Both & 145 & 27.5 & 91 & 17.8 & 236 & 22.7 \\
\hline \multicolumn{7}{|l|}{ Food sources } \\
\hline Farming & 461 & 87.5 & 486 & 94.9 & 947 & 91.1 \\
\hline Purchasing & 66 & 12.5 & 26 & 5.1 & 92 & 8.9 \\
\hline \multicolumn{7}{|l|}{ Child sex } \\
\hline Female & 305 & 57.9 & 273 & 53.3 & 578 & 55.6 \\
\hline Male & 222 & 42.1 & 239 & 46.7 & 461 & 44.4 \\
\hline \multicolumn{7}{|l|}{ Mother age } \\
\hline $15-34$ & 365 & 69.3 & 244 & 47.7 & 609 & 58.6 \\
\hline $35-49$ & 161 & 30.6 & 268 & 52.3 & 429 & 41.3 \\
\hline$\geq 50$ & 1 & .2 & 0 & 0 & 1 & .1 \\
\hline \multicolumn{7}{|l|}{ Child age } \\
\hline $24-35$ & 221 & 41.9 & 230 & 44.9 & 451 & 43.4 \\
\hline $36-47$ & 191 & 36.2 & 167 & 32.6 & 358 & 34.5 \\
\hline $48-59$ & 115 & 21.8 & 115 & 22.5 & 230 & 22.1 \\
\hline \multicolumn{7}{|l|}{ Child birth order } \\
\hline $1-2$ & 197 & 37.4 & 72 & 14.1 & 269 & 25.9 \\
\hline
\end{tabular}


Table 1 Socio-economic and demographic characteristics of the respondents from food secure and food insecure households of Albuko district, northeast Ethiopia, 2017 (Continued)

\begin{tabular}{|c|c|c|c|c|c|c|}
\hline \multirow[t]{2}{*}{ Characteristics } & \multicolumn{2}{|c|}{$\begin{array}{l}\text { Food secure HHs } \\
n=527\end{array}$} & \multicolumn{2}{|c|}{$\begin{array}{l}\text { Food insecure } \mathrm{HHs} \\
n=512\end{array}$} & \multicolumn{2}{|l|}{$\begin{array}{l}\text { Total } \\
n=1039\end{array}$} \\
\hline & Frequency & Percent & Frequency & Percent & Frequency & Percent \\
\hline $3-4$ & 289 & 54.8 & 386 & 75.4 & 675 & 65.0 \\
\hline$>4$ & 41 & 7.8 & 54 & 10.5 & 95 & 9.1 \\
\hline \multicolumn{7}{|l|}{ HH family size } \\
\hline$<4$ & 291 & 55.2 & 192 & 37.5 & 483 & 46.5 \\
\hline$\geq 4$ & 236 & 44.8 & 320 & 62.5 & 556 & 53.5 \\
\hline
\end{tabular}

a Oromo, Tigray

${ }^{\mathrm{b}}$ Divorced, Windowed and Separated

'Trader, Student, Daily worker

lowest prevalence (28.8\%) in the 24-35-month age group. Conversely, the trend of stunting among children from food insecure households (FIHHs) was decreased as the age of children increased. Children 24-35-month old were at higher odds of stunting than children 48-59 month (Table 5).

\section{Factors associated with stunting among preschool children from food secure $\mathrm{HHs}$}

In both the bivariable and multivariable analysis, mother's education, family size, child sex, child birth order and the amount of water used were found to be significantly associated with stunting among preschool

Table 2 Maternal and child health characteristics of the respondents from food secure and food insecure households of Albuko district, northeast Ethiopia, 2017

\begin{tabular}{|c|c|c|c|c|c|c|}
\hline \multirow[t]{2}{*}{ Characteristics } & \multicolumn{2}{|c|}{$\begin{array}{l}\text { Food secure HHs } \\
n=527\end{array}$} & \multicolumn{2}{|c|}{$\begin{array}{l}\text { Food insecure HHs } \\
n=512\end{array}$} & \multicolumn{2}{|l|}{$\begin{array}{l}\text { Total } \\
n=1039\end{array}$} \\
\hline & Frequency & Percent & Frequency & Percent & Frequency & Percent \\
\hline \multicolumn{7}{|c|}{ Extra meal during pregnancy/lactation } \\
\hline Yes & 416 & 78.9 & 201 & 39.3 & 617 & 59.4 \\
\hline No & 111 & 21.1 & 311 & 60.7 & 422 & 40.6 \\
\hline \multicolumn{7}{|l|}{ ANC visit } \\
\hline Yes & 477 & 90.5 & 429 & 83.8 & 906 & 87.2 \\
\hline No & 50 & 9.5 & 83 & 16.2 & 133 & 12.8 \\
\hline \multicolumn{7}{|l|}{ Number of ANC } \\
\hline First & 13 & 2.7 & 14 & 3.2 & 27 & 3 \\
\hline Second & 110 & 23.3 & 101 & 24 & 211 & 24 \\
\hline Third & 164 & 35 & 148 & 34 & 312 & 34 \\
\hline Fourth and more & 190 & 39 & 166 & 38.8 & 356 & 39 \\
\hline \multicolumn{7}{|l|}{ Place of delivery } \\
\hline Home & 182 & 34.5 & 209 & 40.8 & 391 & 37.6 \\
\hline Health facility & 345 & 65.5 & 303 & 59.2 & 648 & 62.4 \\
\hline \multicolumn{7}{|c|}{ Deworming supplementation } \\
\hline Yes & 477 & 90.5 & 465 & 90.8 & 942 & 90.7 \\
\hline No & 50 & 9.5 & 47 & 9.2 & 97 & 9.3 \\
\hline \multicolumn{7}{|c|}{ Vitamin A supplementation in the past six months } \\
\hline Yes & 482 & 91.5 & 459 & 89.6 & 941 & 90.6 \\
\hline No & 45 & 8.5 & 53 & 10.4 & 98 & 9.4 \\
\hline \multicolumn{7}{|c|}{ Diarrheal morbidity in the past two weeks } \\
\hline Yes & 42 & 8.0 & 103 & 20.1 & 145 & 14.0 \\
\hline No & 485 & 92.0 & 409 & 79.9 & 894 & 86.0 \\
\hline
\end{tabular}

ANC antenatal care, $H H$ s households 
Table 3 Child feeding practices of the respondents from food secure and food insecure households of Albuko district, northeast Ethiopia, 2017

\begin{tabular}{|c|c|c|c|c|c|c|}
\hline \multirow[t]{2}{*}{ Characteristics } & \multicolumn{2}{|c|}{$\begin{array}{l}\text { Food secure HHs } \\
n=527\end{array}$} & \multicolumn{2}{|c|}{$\begin{array}{l}\text { Food insecure } \mathrm{HHs} \\
n=512\end{array}$} & \multicolumn{2}{|l|}{$\begin{array}{l}\text { Total } \\
n=1039\end{array}$} \\
\hline & Frequency & Percent & Frequency & Percent & Frequency & $\overline{\text { Percent }}$ \\
\hline \multicolumn{7}{|l|}{ BF initiation } \\
\hline Within one hour & 519 & 98.5 & 502 & 98.0 & 1021 & 98.3 \\
\hline More than one hour & 8 & 1.5 & 10 & 2.0 & 18 & 1.7 \\
\hline \multicolumn{7}{|l|}{ Pre-lacteal use } \\
\hline Yes & 79 & 15.0 & 83 & 16.2 & 162 & 15.6 \\
\hline No & 448 & 85.0 & 429 & 83.8 & 877 & 84.4 \\
\hline \multicolumn{7}{|l|}{ Pre-lacteal food type } \\
\hline Milk & 13 & 16.4 & 0 & 0 & 13 & 8.2 \\
\hline Water & 31 & 39.2 & 43 & 52 & 74 & 45.6 \\
\hline Sugar & 35 & 44.4 & 39 & 47.9 & 74 & 45.6 \\
\hline Honey & 0 & 0 & 1 & 0.1 & 1 & 0.6 \\
\hline \multicolumn{7}{|l|}{ Colostrum use } \\
\hline Yes & 483 & 91.7 & 493 & 96.3 & 976 & 93.9 \\
\hline No & 44 & 8.3 & 19 & 3.7 & 63 & 6.1 \\
\hline \multicolumn{7}{|l|}{ CF initiation } \\
\hline Below six month & 92 & 17.5 & 80 & 15.6 & 172 & 16.6 \\
\hline At six month & 237 & 45.0 & 273 & 53.3 & 510 & 49.1 \\
\hline After six month & 198 & 37.6 & 159 & 31.1 & 357 & 34.4 \\
\hline \multicolumn{7}{|l|}{ Feeding method } \\
\hline Bottle & 110 & 20.9 & 112 & 21.9 & 222 & 21.4 \\
\hline Cup & 231 & 43.8 & 213 & 41.6 & 444 & 42.7 \\
\hline Hand & 169 & 32.1 & 174 & 34.0 & 343 & 33.0 \\
\hline Others $^{\mathrm{a}}$ & 17 & 3.2 & 13 & 2.5 & 30 & 2.9 \\
\hline \multicolumn{7}{|l|}{ Dietary diversity } \\
\hline$<4$ food groups & 368 & 69.8 & 389 & 76.0 & 757 & 72.9 \\
\hline$\geq 4$ food groups & 159 & 30.2 & 123 & 24.0 & 282 & 27.1 \\
\hline \multicolumn{7}{|l|}{ Meal frequency } \\
\hline$<4$ times & 178 & 33.8 & 283 & 55.3 & 461 & 44.4 \\
\hline$\geq 4$ times & 349 & 66.2 & 229 & 44.7 & 578 & 55.6 \\
\hline \multicolumn{7}{|l|}{ Types of food } \\
\hline Injera & 57 & 10.8 & 56 & 10.9 & 113 & 10.9 \\
\hline Milk & 107 & 20.3 & 99 & 19.3 & 206 & 19.8 \\
\hline Porridge & 214 & 40.6 & 257 & 50.2 & 471 & 45.3 \\
\hline Smashed potato & 149 & 28.3 & 100 & 19.5 & 249 & 24.0 \\
\hline
\end{tabular}

BF Breast feeding, CF Complementary feeding

${ }^{a}$ spoon, Dietary diversity: number of food groups consumed by an individual

children from food secure households. Accordingly, preschool children having uneducated mothers and primary school complete were 5.2 and 4.2 times more likely to be stunted than preschool children whose mothers had higher education (secondary and above) $(\mathrm{AOR}=5.24,95 \% \mathrm{CI} ; 2.30-11.91)$ and $(\mathrm{AOR}=4.2,95 \%$ CI; 1.77-9.97), respectively. Likewise, increased odds of stunting were observed among children from four and more family member households $(\mathrm{AOR}=4.33$, 95\% CI; 2.92-6.41) and children in fourth and above birth order $(\mathrm{AOR}=2.25,95 \% \mathrm{CI} ; 1.03-4.92)$. In addition, male sex increased the likelihood of developing stunting 1.67 more times $(\mathrm{AOR}=1.67,95 \% \mathrm{CI}$; 1.13-2.47) (Table 6). 
Table 4 Water source, sanitation and hygienic characteristics of the respondents from food secure and food insecure households of Albuko district, northeast Ethiopia, 2017

\begin{tabular}{|c|c|c|c|c|c|c|}
\hline \multirow[t]{2}{*}{ Characteristics } & \multicolumn{2}{|c|}{$\begin{array}{l}\text { Food secure HHs } \\
n=527\end{array}$} & \multicolumn{2}{|c|}{$\begin{array}{l}\text { Food insecure } \mathrm{HHs} \\
n=512\end{array}$} & \multicolumn{2}{|l|}{$\begin{array}{l}\text { Total } \\
n=1039\end{array}$} \\
\hline & Frequency & Percent & Frequency & Percent & Frequency & Percent \\
\hline \multicolumn{7}{|l|}{ Sources of water } \\
\hline Protected source & 477 & 90.5 & 441 & 86.1 & 918 & 88.4 \\
\hline Unprotected source & 50 & 9.5 & 71 & 13.9 & 121 & 11.6 \\
\hline \multicolumn{7}{|c|}{ Amount of water used (litter) } \\
\hline$<40$ & 201 & 38.1 & 194 & 37.9 & 395 & 38.0 \\
\hline$\geq 40$ & 326 & 61.8 & 318 & 62.1 & 644 & 61.9 \\
\hline \multicolumn{7}{|c|}{ Time spent to water (minutes) } \\
\hline$<30$ & 363 & 68.9 & 346 & 67.6 & 709 & 68.2 \\
\hline$\geq 30$ & 164 & 31.1 & 166 & 32.4 & 330 & 31.8 \\
\hline \multicolumn{7}{|l|}{ Latrine availability } \\
\hline Yes & 413 & 78.4 & 476 & 93.0 & 889 & 85.6 \\
\hline No & 114 & 21.6 & 36 & 7.0 & 150 & 14.4 \\
\hline \multicolumn{7}{|l|}{ Types of latrine } \\
\hline Pit & 409 & 99.1 & 464 & 97.4 & 873 & 98.2 \\
\hline Flush & 0 & 0 & 2 & 0.4 & 2 & 0.2 \\
\hline Ventilated improved & 4 & 0.9 & 10 & 2.2 & 14 & 1.6 \\
\hline
\end{tabular}

HHs households

Time spent to water: the time it takes to reach to water source (for single trip)

\section{Factors associated with stunting among preschool}

\section{children from food insecure $\mathrm{HHs}$}

In the multivariable analysis, level of maternal education, family size, extra meal consumption during pregnancy/ lactation, child sex, child age, and dietary diversity score were significantly associated with stunting among preschool children from food insecure HHs.

The risk of being stunted was 3 times more likely among preschool children from uneducated mothers compared to preschool children from educated mothers (secondary and above education) $(\mathrm{AOR}=3.07,95 \% \mathrm{CI}$;
1.40-6.75). Preschool children in households of four and more family members, $(\mathrm{AOR}=3.64,95 \% \mathrm{CI} ; 2.37-5.58)$ male sex $(\mathrm{AOR}=1.73,95 \% \mathrm{CI} ; 1.16,2.58)$, and 24-36-month age group $(\mathrm{AOR}=2.37,95 \% \mathrm{CI} ; 1.41,3.99)$ were significantly associated with stunting (Table 7).

\section{Factors associated with stunting among preschool children (whole sample population)}

The present study revealed that, maternal education, family size, sex of child, and extra meal consumption during pregnancy/lactation were found to be significantly associated

Table 5 Prevalence of stunting among preschool children from food secure and food insecure households of Albuko district, northeast Ethiopia, 2017

\begin{tabular}{|c|c|c|c|c|c|c|c|c|c|}
\hline \multirow[t]{3}{*}{ Characteristics } & \multicolumn{3}{|c|}{ Food secure $(n=527)$} & \multicolumn{3}{|c|}{ Food insecure $(n=512)$} & \multicolumn{3}{|c|}{ Total $(n=1039)$} \\
\hline & \multirow[t]{2}{*}{ Number } & \multicolumn{2}{|c|}{ Height-for-age (\%) } & \multirow[t]{2}{*}{ Number } & \multicolumn{2}{|c|}{ Height-for-age (\%) } & \multirow[t]{2}{*}{ Number } & \multicolumn{2}{|c|}{ Height-for-age (\%) } \\
\hline & & $\%<-3 \mathrm{SD}$ & $\%<-2 S D$ & & $\%<-3 \mathrm{SD}$ & $\%<-2 S D$ & & $\%<-3 S D$ & $\%<-2 \mathrm{SD}$ \\
\hline \multicolumn{10}{|l|}{ Age } \\
\hline $24-35$ & 132 & 17.4 & 28.8 & 137 & 32.8 & 51.8 & 269 & 25.3 & 40.5 \\
\hline $36-47$ & 209 & 16.7 & 36.4 & 183 & 22.4 & 41 & 392 & 19.4 & 38.5 \\
\hline $48-59$ & 186 & 21.5 & 40.3 & 192 & 22.4 & 38 & 378 & 22 & 39.2 \\
\hline \multicolumn{10}{|l|}{ Sex } \\
\hline Male & 222 & 23.9 & 42.8 & 239 & 28.9 & 50.2 & 461 & 26.5 & 46.6 \\
\hline Female & 305 & 14.8 & 30.8 & 273 & 22 & 36.3 & 578 & 18.2 & 33.4 \\
\hline Total & 527 & 18.6 & 35.9 & 512 & 25.2 & 42.8 & 1039 & 21.8 & 39.3 \\
\hline
\end{tabular}

SD standard deviation 
Table 6 Factors Associated with stunting among food secure households in preschool children of Albuko district, northeast Ethiopia, $2017(n=527)$

\begin{tabular}{|c|c|c|c|c|}
\hline \multirow[t]{2}{*}{ Characteristics } & \multicolumn{2}{|l|}{ Stunting } & \multirow[t]{2}{*}{ COR (95\%) } & \multirow[t]{2}{*}{ AOR (95\%) } \\
\hline & Yes (\%) & No $(\%)$ & & \\
\hline \multicolumn{5}{|l|}{ Mother education } \\
\hline Uneducated & $129(39.6)$ & $197(60.4)$ & $3.77(1.721-8.24)$ & $5.24(2.30-11.91) * * *$ \\
\hline Primary & $52(35)$ & $95(65)$ & $3.15(1.38-7.17)$ & $4.200(1.77-9.97) * * *$ \\
\hline Secondary and above & $8(14.8)$ & $46(85.2)$ & 1 & 1 \\
\hline \multicolumn{5}{|l|}{ Family size } \\
\hline$<4$ & $65(22.3)$ & $226(77.7)$ & 1 & 1 \\
\hline$\geq 4$ & $124(52.5)$ & $112(47.5)$ & $3.85(2.64-5.61)$ & $4.33(2.92-6.41) * * *$ \\
\hline \multicolumn{5}{|c|}{ Extra food during pregnancy/lactation } \\
\hline Yes & $138(33)$ & $278(67)$ & 1 & 1 \\
\hline No & $51(45.9)$ & $60(54.1)$ & $1.71(1.12-2.62)$ & $1.19(0.72-1.95)$ \\
\hline \multicolumn{5}{|l|}{ Child sex } \\
\hline Female & $94(30.8)$ & $211(69.2)$ & 1 & 1 \\
\hline Male & $95(42.7)$ & $127(57.3)$ & $1.68(1.17-2.41)$ & $1.67(1.13-2.47)^{* *}$ \\
\hline \multicolumn{5}{|l|}{ Child birth order } \\
\hline $1-2$ & $51(25.8)$ & $146(74.2)$ & 1 & 1 \\
\hline $3-4$ & $114(39.4)$ & $175(60.6)$ & $1.87(1.25-2.77)$ & $1.14(0.72-1.80)$ \\
\hline$>4$ & $24(58.5)$ & $17(41.5)$ & $4.04(2.01-8.13)$ & $2.25(1.03-4.92) *$ \\
\hline \multicolumn{5}{|c|}{ Amount of water used (litter) } \\
\hline$<40$ & $84(41.7)$ & $117(58.3)$ & $1.51(1.05-2.18)$ & $1.58(1.06-2.34) *$ \\
\hline$\geq 40$ & $105(32.2)$ & $221(67.8)$ & 1 & 1 \\
\hline \multicolumn{5}{|c|}{ Time spent to water (minutes) } \\
\hline$<30$ & $123(33.8)$ & $240(66.2)$ & 1 & 1 \\
\hline$\geq 30$ & $66(40.2)$ & $98(59.8)$ & $1.31(0.90-1.92)$ & $1.29(0.84-1.98)$ \\
\hline
\end{tabular}

Hosmer-Lemeshow test $p$ value $=0.74$

Time spent to water; the time it takes to reach to water source (for single trip)

$\left(1.00=\right.$ Reference $\left.^{* * *}=p<0.001^{* *}=p<0.01^{*}=p<0.05\right)$

with stunting among preschool children during the multivariable analysis in the final model.

The risk of being stunted for preschool children whose mothers were uneducated and primary school level were 4.38 and 2.1 times more than in preschool children whose mothers had secondary and above education $(\mathrm{AOR}=4.38,95 \% \mathrm{CI} ; 2.51,7.66)$ and $(\mathrm{AOR}=2.10,95 \%$ CI; 1.17, 3.79). Preschool children in households of four and more members were 3.4 times more likely to be stunted compared to children in less than four family members $(\mathrm{AOR}=3.47,95 \% \mathrm{CI} ; 2.62,4.60)$. Furthermore, the analysis of logistic regression revealed that male sex increased the likelihood of stunting by 1.71 times compared to female sex $(\mathrm{AOR}=1.71,95 \% \mathrm{CI} ; 1.30,2.24)$ (Table 8).

\section{Discussion}

The result of the present study showed that the prevalence of stunting among preschool children from both food secure and food insecure households in the community was high which clearly confirming that currently chronic malnutrition (stunting) is a widespread public health problem significance in the study area. Poor breastfeeding practices, poor complementary feeding, low level health seeking behaviours, close birth spacing, low parental education, and low wealth status (poor socio-economic status) are some of the factors which precipitate the problem [37].

The prevalence of stunting was found to be high among preschool children from both food secure and food insecure households (35.9\%, 95\%CI; 31.7, 40.1) and $(42.8 \%, 95 \% \mathrm{CI} ; 38.4,47.2)$ respectively. Of these, $18.6 \%$ preschool children from FSHHs and 25.2\% from FIHHs were severely stunted.

The findings of this study were consistent with those of other local studies from East and West Gojjam, Ethiopia which reported a stunting prevalence of $37.5 \%$ and 38.3\% among children from food secure and food insecure households (FSHHs and FIHHs), respectively and reported no significant variations among both groups [34]. This similarity may be due to contextual 
Table 7 Associated factors of stunting among preschool children from food insecure households of Albuko district, northeast Ethiopia, $2017(n=512)$

\begin{tabular}{|c|c|c|c|c|}
\hline \multirow[t]{2}{*}{ Characteristics } & \multicolumn{2}{|l|}{ Stunting } & \multirow[t]{2}{*}{$\operatorname{COR}(95 \%)$} & \multirow[t]{2}{*}{ AOR (95\%) } \\
\hline & Yes (\%) & No (\%) & & \\
\hline \multicolumn{5}{|l|}{ Mother education } \\
\hline Uneducated & $160(53.6)$ & $139(46.4)$ & $3.80(1.81-7.99)$ & $3.08(1.40-6.76) * *$ \\
\hline Primary & $49(28.9)$ & $121(71.1)$ & $1.34(0.61-2.92)$ & $0.97(0.42-2.22)$ \\
\hline Secondary and above & $10(23.3)$ & $33(76.7)$ & 1 & 1 \\
\hline \multicolumn{5}{|l|}{ Family size } \\
\hline$<4$ & $50(26.1)$ & $142(73.9)$ & 1 & 1 \\
\hline$\geq 4$ & $169(52.8)$ & $151(47.2)$ & $3.18(2.15-4.69)$ & $3.64(2.37-5.58) * * *$ \\
\hline \multicolumn{5}{|c|}{ Extra food during pregnancy/lactation } \\
\hline Yes & $72(35.8)$ & $129(64.2)$ & 1 & 1 \\
\hline No & $147(47.3)$ & $164(52.7)$ & $1.61(1.12-2.31)$ & $1.71(1.14-2.58) * *$ \\
\hline \multicolumn{5}{|l|}{ Child sex } \\
\hline Female & $99(36.3)$ & $174(63.7)$ & 1 & 1 \\
\hline Male & $120(50.2)$ & $119(49.8)$ & $1.77(1.24-2.53)$ & $1.73(1.17-2.58) * *$ \\
\hline \multicolumn{5}{|l|}{ Child age } \\
\hline $24-35$ & $119(51.8)$ & $111(48.2)$ & $2.26(1.41-3.61)$ & $2.37(1.41-3.99) * * *$ \\
\hline $36-47$ & $63(37.7)$ & $104(62.3)$ & $1.28(0.77-2.11)$ & $1.47(0.84-2.58)$ \\
\hline $49-59$ & $37(32.2)$ & $78(67.8)$ & 1 & 1 \\
\hline \multicolumn{5}{|l|}{ Dietary diversity score } \\
\hline$<4$ food groups & $180(46.3)$ & $209(53.7)$ & $1.86(1.21-2.85)$ & $1.92(1.20-3.09) * *$ \\
\hline$\geq 4$ food groups & $39(31.8)$ & $84(68.2)$ & 1 & 1 \\
\hline \multicolumn{5}{|l|}{ Meal frequency/day } \\
\hline$<4$ times & $132(46.7)$ & $151(53.3)$ & $1.43(1.00-2.03)$ & $1.18(0.78-1.80)$ \\
\hline$\geq 4$ times & $87(38)$ & $142(62)$ & 1 & 1 \\
\hline
\end{tabular}

Hosmer-Lemeshow test $p$ value $=0.37$

Dietary diversity score: the sum total of food groups consumed by an individual in the past 24 hours

$\left(1.00=\right.$ Reference $\left.^{* * *}=p<0.001^{* *}=p<0.01^{*}=p<0.05\right)$

similarities in socio- demographic and economic characteristics, and feeding pattern of children of the study areas.

On the other hand, the level of stunting among food insecure HHs (42.8\%) and food secure HHs (35.9\%) in the present study was lower than those of studies conducted in other parts of Ethiopia. For example, Tigray reported $52 \%$ and $46.1 \%$ prevalence of stunting among children from FIHHs and FSHHs, respectively [38], and Shewa, reported $54.2 \%$ and $46.7 \%$ among children from FIHHs and FSHHs, respectively [39]. The possible reason for these discrepancies might be the fact that as Albuko is one of the districts in which community based nutrition intervention has been implemented for a long period of time which in turn expose the community to be aware of nutritional interventions thereby it has contributing to the reduction of stunting and other forms of malnutrition in the study are. Additionally, there were high maternal illiteracy rate and most of the mothers were housewives among the studies done in Tigray and
Shewa of Ethiopia. The overall prevalence of stunting in this study was $39.3 \%$ (95\% CI:36.3, 42.3). The prevalence of severe stunting was $21.8 \%$. The finding of this study was consistent with the national prevalence of stunting (38\%, EDHS report, 2016) for children under five years [8]. Again, the current finding was also in agreement with that of a baseline survey report for Infant and Young Child Feeding Program 2014, conducted in Albuko district, Ethiopia, by Alive and Thrive and reported a stunting prevalence of $38 \%$ [40]. However, the overall stunting prevalence $(39.3 \%)$ of the present study was lower than that of Amhara Region (46\%), Ethiopia [8].

Conversely, this study showed a higher stunting prevalence compared with that of Ethiopian Somali Region reported a stunting prevalence of $22.9 \%$ [41] and Gambella, Ethiopia reported $33.7 \%$ of prevalence [42]. The possible reason for the occurrence of the difference between the current and previous studies may be arisen from the age groups of study subjects included. For the present study, children between the age group of 24-59 months were 
Table 8 Associated factors of stunting among preschool children from FSHHs and FlHHs of Albuko district, northeast Ethiopia, 2017 $(n=1039)$

\begin{tabular}{|c|c|c|c|c|}
\hline \multirow[t]{2}{*}{ Characteristics } & \multicolumn{2}{|l|}{ Stunting } & \multirow[t]{2}{*}{ COR (95\%) } & \multirow[t]{2}{*}{ AOR (95\%) } \\
\hline & $\overline{Y e s}(\%)$ & No (\%) & & \\
\hline \multicolumn{5}{|l|}{ Mother education } \\
\hline Uneducated & $289(46.3)$ & $336(53.7)$ & $3.78(2.21-6.45)$ & $4.38(2.51-7.66) * * *$ \\
\hline Primary & $101(31.9)$ & $216(68.1)$ & $2.05(1.17-3.61)$ & $2.11(1.17-3.79) *$ \\
\hline Secondary and above & $18(18.6)$ & $79(81.4)$ & 1 & 1 \\
\hline \multicolumn{5}{|l|}{ HHFS status } \\
\hline Secure & $219(40.3)$ & $324(59.7)$ & 1 & 1 \\
\hline Insecure & $189(38.1)$ & $307(61.9)$ & $1.10(0.86-1.41)$ & $1.09(0.84-1.44)$ \\
\hline \multicolumn{5}{|l|}{ Family size } \\
\hline$<4$ & $115(23.8)$ & $368(76.2)$ & 1 & 1 \\
\hline$\geq 4$ & $293(52.7)$ & $263(47.3)$ & $3.565(2.73-4.66)$ & $3.47(2.62-4.60) * * *$ \\
\hline \multicolumn{5}{|c|}{ Extra food during pregnancy/lactation } \\
\hline Yes & $198(47)$ & $224(53)$ & 1 & 1 \\
\hline No & $210(34.1)$ & $407(65.9)$ & $1.71(1.33-2.21)$ & $1.44(1.09-1.90) * *$ \\
\hline \multicolumn{5}{|l|}{ Child sex } \\
\hline Female & $193(33.4)$ & 385 (66.6) & 1 & 1 \\
\hline Male & $215(46.7)$ & $246(53.3)$ & $1.74(1.36-2.24)$ & $1.71(1.30-2.24) * * *$ \\
\hline \multicolumn{5}{|l|}{ Child age } \\
\hline $24-35$ & $192(42.6)$ & $259(57.4)$ & 1.39 (1.00-1.93) & $1.33(0.93-1.91)$ \\
\hline $36-47$ & $136(38)$ & $222(62)$ & $1.15(0.81-1.62)$ & $1.151(0.79-1.68)$ \\
\hline $48-59$ & $80(34.8)$ & $150(65.2)$ & 1 & 1 \\
\hline \multicolumn{5}{|l|}{ Dietary diversity } \\
\hline$<4$ food groups & $313(41.4)$ & $444(58.6)$ & $1.39(1.04-1.85)$ & $1.34(0.98-1.83)$ \\
\hline$\geq 4$ food groups & $95(33.7)$ & $187(66.3)$ & 1 & 1 \\
\hline \multicolumn{5}{|l|}{ Meal frequency/day } \\
\hline$<4$ times & $202(43.9)$ & $259(56.1)$ & $1.41(1.10-1.81)$ & $1.03(0.77-1.38)$ \\
\hline$\geq 4$ times & $206(35.6)$ & $372(64.4)$ & 1 & 1 \\
\hline \multicolumn{5}{|l|}{ Time spent to water } \\
\hline$<30$ minutes & $266(37.6)$ & $443(62.4)$ & 1 & 1 \\
\hline$\geq 30$ minutes & $142(43.1)$ & $188(56.9)$ & $1.26(0.96-1.64)$ & $1.23(0.92-1.64)$ \\
\hline
\end{tabular}

Hosmer-Lemeshow test $\mathrm{p}$ value $=0.55$

HHFS; Household Food Security status

Time spent to water: the time it takes to reach to water source (for a single trip)

$\left(1.00=\right.$ Reference $\left.^{* * *}=p<0.001^{* *}=p<0.01^{*}=p<0.05\right)$

included while the previous studies included children less than 24 months. Stunting for children under age 5 sharply increases between age 6 and 23 months, and peaks at age 24-35 months [8]. Hence, the prevalence of stunting in this study might be overestimated by the inclusion of older children as compared to those studies. Most of the mothers in this study were uneducated and housewives. Higher odds of stunting was observed among children whose mothers were illiterate $[43,44]$.

In the present study, mother's education, family size, child sex were factors associated with stunting among preschool children from both FSHHs and FIHHs during multivariable analysis which was analyzed separately. Child birth order and the amount of water ( $<30$ litters) used per day showed an associated with stunted children from food secure households, whereas, extra meal during pregnancy/lactation, child age, and low dietary diversity score of less than the WHO recommendation were predictors of stunting in children from food insecure households.

In the overall model among the variables fitted to the multivariable analysis, only four independent variables, namely maternal education, family size, extra meal taking during pregnancy or lactation, and child sex remained 
positively associated with child stunting, whereas household food security status, age of the child, and child's dietary diversity did not show an association with child stunting. The odds of stunting were higher among children from uneducated mothers than educated mothers 4.38 ( $\mathrm{AOR}=4.38,95 \% \mathrm{CI}: 2.51-7.66)$. The finding was parallel with EDHS 2016 report which revealed that higher stunting rate (42\%) was observed among children who were from illiterate mothers as compared to those children who were from literate mothers (17\%) [8]. Similar research findings in Ethiopia were also reported by other studies which tried to show mothers' education was emerged as the key predictor of stunting $[34,45]$. It is argued that educated mothers have higher nutritional knowledge which intern contributed to child feeding practices of mothers and finally helped them to have a well-nourished children but, mothers with no formal education were do not [45].

Children from four and above family members were more likely to be stunted as compared to children from less than four family members. Studies from Tigray Region, Ethiopia [38] and India [46] reported similar results. The association between large family size and stunting among preschool children can be partially explained by as the number of families increased in the household, the food consumption and expenditure will also be increased. As a result, the probability of children getting adequate nutrition and energy will be less despite the fact that children needs more energy and micronutrient to support their rapid growth and development. Hence, unable to supply the necessary energy and micronutrient requirements by children for a prolonged period eventually leads to development of manifestation of chronic malnutrition or stunting. Furthermore, Families with more children generally devote less time to care their children [37, 47].

The habits of taking extra meals during pregnancy or lactation was also an associated factor for stunting in that children born to mothers who did not take extra meals during pregnancy or lactation were 1.44 times more likely to be stunted than children of mothers who had taken extra meals during pregnancy or lactation $(\mathrm{AOR}=1.437,95 \% \mathrm{CI}: 1.089-1.895)$. This is true as women of reproductive age are especially vulnerable to chronic energy deficiency because they have a high nutrient needs and lack of adequate nutrients during pregnancy and breast feeding put the baby at a higher risk of being stunted [8]. But it should be noted that taking extra meal was measured by asking the mother's recall for the previous pregnancy or lactation period for the study child. As a result, it cannot be measured and difficult to ascertain whether it was taken during pregnancy, lactation or during both periods by the mother.
Stunting prevalence cross sectional studies in Ethiopia [43, 44] , EDHS 2016 report [8], and from Sub Saharan Africa $[48,49]$ reported that the prevalence of stunting among under five male children was consistently higher than among under five female children. The present study also found a similar result that the odds of being stunted were 1.71 times higher among under five male children than among under five female children. (AOR = 1.708, 95\% CI: 1.302-2.240). This result could be due to unmeasured factors like parental gender preference or sex difference (perceived higher needs for boys) in feeding practice. In addition to behavioral differences, there might be biological differences. However, up to today mechanisms underlying sex difference in stunting prevalence are poorly understood [50].

In the multivariable logistic regression analysis of the final model, ANC visits and availability of latrine were among the factors that were not associated with stunting. The absence of association between ANC visits and stunting may be partially explained by there was no difference in ANC visits between mothers from FSHHs and FIHHs. Information on ANC visits was collected from the mother's recall for the previous pregnancy for the study child. However, all of these information given by mother may not be belonging to the study child (if the study child was not the previous pregnancy) due to the fact that the mother might not be able to remember or differentiate for which her previous pregnancy or child she had followed an ANC. As a result, the mother may report her ANC visits for the younger siblings rather than for the study child.

Greater FIHHs had a latrine than their counterparts. This may be due to the PSNP enforces the beneficiaries to construct more latrines and the difference in educational level of the mothers as more educated mothers were from FIHHs.

The current study finding revealed out no difference was observed among under five children as being from Productive Safety Net Program (PSNP) beneficiaries or FIHHs and non-beneficiaries (FSHHs) in terms of their stunting status. that the two comparative groups were not different significantly. According to this study finding, being a food secured household did not show any association with child stunting. This finding was in line with study reports from in Ethiopian and Brazil which showed the absence of association [34, 51]. The absence of association might be because of other factors that directly or indirectly affect the nutritional status of children [52]. The absence of association in this study may further be explanation by the presence of an opposite trend of stunting prevalence across children's age groups in FSHHs and FIHHs. Less number of stunted children and high proportion of stunted children were noticed among the youngest and older age categories in FSHHs respectively. 
While the rate of stunting was higher in the youngest and its rate reduced in the older age categories in FIHHs. Following the opposite trend of stunting between the two groups the association might be masked when the two groups analysed together in the overall model analysis. Furthermore, community based nutrition, IYCF, National Nutrition Program (NNP) and water, sanitation and hygiene interventions which are currently implemented in the study area along with the PSNP can also be mentioned as a reason for the absence of significant association between household food security status and child stunting status.

\section{Limitation of the study}

The current study has addressed its objectives to determine the prevalence of stunting and factors associated with it among preschool children aged 24-59 months in the Rural community of Albuko district, northeast Ethiopia. Due to a cross-sectional design, it was difficult to examine any potential temporal relationships. Since the study included children aged 24-59 months there is a potential recall bias among respondents answering questions relating to events happening in the past two years and above. As for example; ANC visits, taking extra meal during pregnancy or lactation, vitamin A and deworming supplementations and dietary diversity of children in the past 24 hours. In addition, the study is not free from measurement errors during measuring height and determining age of the children although a pre-test, instrument calibration, training of data collectors and close supervisions during data collection were carried out to minimize bias. Finally, information on some important confounding variables such as maternal nutrition status, minimum dietary diversity for women, hand washing practice among mothers and other forms of undernutrition (wasting and underweight) among preschool children were not collected.

\section{Conclusion}

Based on the findings of the current study, it can be concluded that the rate of stunting was high among preschool children in the study area confirming that stunting still remains a public health problem in Albuko district even though it is declining from $44 \%$ in 2011 to $38 \%$ in 2016 among under five children $[7,8]$. Though PSNP is a proven strategy in reducing the burden of childhood stunting, this study showed that there is no significant variation in the magnitude of stunting. However, it does not mean that PSNP intervention is not important in reducing the burden of stunting. Furthermore, the etiology of stunting is multifactorial and thus food security cannot capture all factors at work. Therefore, enhancing maternal education, maternal nutrition and utilization of family planning services are some of the critical interventions to curb chronic nutrition problems among preschool children.

\section{Abbreviations}

ANC: Ante Natal Care; AOR: Adjusted Odds Ratio; Cl: Confidence Interval; COR: Crude Odds Ratio; DDS: Dietary Diversity Score; EDHS: Ethiopian Demographic Health Survey; ENA: Emergency Nutrition Assessment; FANTA: Food and nutrition technical assistant; FAO: Food and Agricultural Organization; FlHHs: Food insecure households; FSHHs: Food secure households; GTP: Growth and Transformation Plan; HAZ: Height for age Zscore; HHFS: Household food security; HHs: Households; IYCF: Infant and young child feeding; NNP: National Nutrition Program; PSNP: Productive Safety Net Program; SD: Standard Deviation; SDGs: Sustainable Development Goals; SPSS: Statistical Package for Social Sciences; SUN: Scaling Up Nutrition; UNCEF: United Nation Children's Fund; WHA: World Health Assembly; WHO: World Health Organization

\section{Acknowledgments}

We would like to thank study participants, data collectors, and supervisors who were involved in this study and spent their valuable time responding to our questionnaire.

\section{Availability of data and materials}

Data will be available upon request from the corresponding author.

\section{Authors' contributions}

GB conceived the idea of the study, developed the tool, managed data collection, analyses, interpretation, and drafted the manuscript. SM assisted with tool development, data analysis and interpretation and critically reviewed the manuscript. MS conceptualized and assisted with design of the study, tool development, as well as participated in the statistical analysis, data interpretation and drafted the manuscript. All authors read and approved the final manuscript.

\section{Ethics approval and consent to participate}

Ethical approval was obtained from Institutional Review Board of University of Gondar. Permission letter was secured from South Wollo Zonal Health Department and from Alboku Health office. Written consent and thump print were taken from each children's mother (study participants) and a consent was obtained for those mothers who age was less than 18 years from their parents after the purpose of the study had been explained. They were informed to withdraw at any time and/or to refrain from responding to questions. Study participants were also informed that all the data obtained from them would be kept confidential using codes instead of any personal identifiers.

\section{Consent for publication}

Not applicable

\section{Competing interests}

The authors declare that they have no competing interests.

\section{Publisher's Note}

Springer Nature remains neutral with regard to jurisdictional claims in published maps and institutional affiliations.

\section{Author details}

${ }^{1}$ Albuko district health office, South Wollo, Albuko, Ethiopia. ${ }^{2}$ Department of Human Nutrition, Institute of Public Health, College of Medicine and Health Sciences, University of Gondar, Gondar, Ethiopia.

Received: 21 November 2017 Accepted: 21 June 2018

Published online: 05 July 2018

\section{References}

1. Alemu Mekonnen NJ, Bekele Tefera. Tackling Child Malnutrition in Ethiopia: Do the Sustainable Development Poverty Reduction Programme's underlying policy assumptions reflect local realities?. WO R K I N G P A P E R 2004;no. 19.

2. Silva P. Environmental Factors and Children's Malnutrition in Ethiopia. World Bank, Environment Department. World Bank Policy Research Working Paper 3489. 2005.

3. Food and Agriculture Organization of the United Nations IFfAD, Unicef, World Food Program, World Health Organization. THE STATE OF FOOD 
SECURITY AND NUTRITION IN THE WORLD. BUILDING RESILIENCE FOR PEACE AND FOOD SECURITY, Rome, FAO. 2017.

4. Meerman J, Carisma B, Thompson B. Global, Regional and Subregional Trends in Undernourishment and Malnutrition. SOFA FOA. 2012;1:1-33.

5. UNICEF. Improving Child Nutrition: The Achievable Imperative Goal for Global Progress. New York: UNICEF; 2013.

6. Federal Democratic Republic of Ethiopia. Seqota Declaration Implementation Plan 2016-2030. February 2016.

7. Ethiopia Central Statistical Authority and ORC Macro. Ethiopia Demographic and Health Survey 2011. Ethiopia and Calverton: Addis Ababa Maryland; 2011.

8. Ethiopia Central Statistical Authority and ORC Macro. Ethiopia Demographic and Health Survey 2016 key Indicator Report. Ethiopia and Calverton: Addis Ababa Maryland; 2016.

9. Alderman $\mathrm{H}$. ea. Long-term consequences of early childhood malnutrition II. FCND Discussion Paper No 168, IFPRI. 2003.

10. Pollitt E GK, Engle PL, Martorell R, Rivera J, Wachs TD, Scrimshaw NS. Early supplementary feeding and cognition: effects over two decades. Monogr Soc Res Child Dev. 1993;58(7): i-118.

11. Moock PRLJ. Childhood malnutrition and schooling in the Terai region of Nepal. J Dev Econ. 1986;20(1):33-52.

12. Federal Democratic Republic of Ethiopia. The Cost of Hunger in Ethiopia. Addis Abeba: The Social and Economic Impact of Child Undernutrition in Ethiopia Summary Report; 2009.

13. UNICEF. UNICEF's approach to scaling up nutrition for mothers and their children. UNICEF, New York: Discussion paper. Programme Division; June 2015.

14. Food and Agriculture Organization of the United Nations Pb. June, 2006; issue 2.

15. UNICEF. UNICEF Policy Review Strategy for Improved Nutrition of Childeren and Women in Developing Country. New York USA; 1990.

16. Ecker $\mathrm{O}$, Breisinger $\mathrm{C}$. The food security system: A new conceptual framework. International Food Policy Research Institute (IFPRI). 2012;

17. Coll-Black S, Gilligan DO, Hoddinott J, Kumar N, Taffesse AS, Wiseman W. Targeting Food Security Interventions When "Everyone is Poor": The Case of Ethiopias Productive Safety Net Programme. ESSP II Working. 2011;24

18. Ibironke Olofin CMM, Majid Ezzati, Seth Flaxman, Robert E. Black, Wafaie W. Fawzi, Laura E. Caulfield, Goodarz Danaei. Associations of Suboptimal Growth with All-Cause and Cause-Specific Mortality in Children under Five Years: A Pooled Analysis of Ten Prospective Studies. PLoS ONE 8(5): e64636 doi:101371/journalpone0064636. 2013.

19. ESAR. UNICEF Regional Advocacy Strategy for Eastern and Southern Africa 2014-2017. Priority 2 Reducing Stunting, p. 3 and Headey (Ethiopia Strategy Support Program), An Analysis of Trends and Determinants of Child Undernutrition in Ethiopia, 2000-2011. 2014 p. 7.

20. UNDP. The United Nations Development Programme, Sustainable Development Goals. 2015.

21. FAO WHO. United Nations Decade of Action on Nutrition (2016-2025). April 2016

22. African Union Summit in Malabo EG. Malabo Declaration on Accelerated Agricultural Growth and Transformation for Shared Prosperity and Improved Livelihoods. June 2014

23. SUN. Scaling Up Nutrition Movment Strategy 2012-2015. September 2012.

24. Onis MD, Borghi KG, Onyango E, Adelheid W, Blössner MD, Piwoz B, Francesco EB. The World Health Organization's Global Target For Reducing Childhood Stunting by 2025: Rationale and Proposed Actions. Maternal \& Child Nutrition. 2013;9(S2):6-26.

25. Government of the Federal Democratic and Republic of Ethiopia. National Nutrition Program June 2013 -June 2015.

26. Federal Ministry of Health. Ethiopian National Strategy on Infant and Young Child Feeding. 2004

27. Ethiopia Ministry of Agriculture. Productive Safety Net Programme Phase IV Programme Implementation Manual. December 2014.

28. Ethiopia Ministry of Agriculture and Rural Development. Food Security Programme 2010-2014 Productive Safety Net. August 2009.

29. Devereux S, Sabates-Wheeler R, Slater R, Tefera M, Brown T, Teshome A. Ethiopia's Productive Safety Net Programme (PSNP): 2008 Assessment Report. Sussex: IDS; 2008.

30. Debela BL, Shively G, Holden ST. Does Ethiopia's Productive Safety Net Program Improve Child Nutrition? Food Security. 2015;7(6):1273-89.

31. Albuko disrict administration office annual report. 2016.

32. Albuko District Finance and Development plan. 2016.

33. Albuko disrict administration office, disaster and risk management office, early warning and response cluster. 2016.
34. Motbainor A, Worku A, Kumie A. Stunting is Associated With Food Diversity While Wasting With Food Insecurity Among Underfive Children in East and West Gojjam Zones of Amhara Region. Ethiopia. PloS one. 2015;10(8): e0133542.

35. UNICEF WHO. WHO Child Growth Standards and Identification of Severe Acute Malnutrition in Infants and Children: A Joint statement by theWorld Health Organization and the United Nations Children's Fund. Geneva, Switzerland: World Health Organization Press; 2009.

36. WHO. Indicators for assessing infant and young child feeding practices part 3 Country Profiles. 2010.

37. Macharia CWK-M, W Muroki, NM. A Comparative Study on The Nutritional Status of Children (6-59 months) in a World Vision Project Area and a NonProject Area in Kathonzweni Division, Makueni District, Kenya. African Journal of Food, Agriculture, Nutrition and Development. 2005;5(1).

38. Kahsay AM. Afework Seid, Omer. Nutritional Status of Children (6-59 months) From Food Secure and Food Insecure Households in Rural Communities of Saesie Tsaeda-Emba District, Tigray, North Ethiopia: Comparative Study. International Journal of Nutrition and Food Sciences. 2015;4(1):51-65.

39. Aweke K, Habtamu F, Akalu G. Nutritional Status of Children in Food Insecure Households in Two Districts of North Showa Zone, Ethiopia. African Journal of Food, Agriculture, Nutrition and Development. 2012;12(2): 5915-27.

40. Alive and Thrive baseline survey for infant and young child feeding program in Albuko district.

41. Yirgu Fekadu AM, Demewoz Haile and Barbara J. Stoecker. Factors associated with nutritional status of infants and young children in Somali Region, Ethiopia: a cross- sectional study. BMC Public Health. 2015;15:846.

42. Jemal Z, Hassen K, T W. Household Food Insecurity and its Association with Nutritional Status among Preschool Children in Gambella Town,Western Ethiopia. J Nutr Food Sci 6: 566. 2016.

43. Dereje Desalegn GE, Yoseph Halala. Prevalence of stunting and associated factors among children aged 6 to 59 months in Areka town, Wolaita Zone, Southern Ethiopia. Journal of Medicine, Physiology and Biophysics An International Peer-reviewed Journal. 2016;21.

44. Tariku A, Woldie H, Fekadu A, Adane AA, Ferede AT, Yitayew S. Nearly Half of Preschool Children are Stunted in Dembia District, Northwest Ethiopia: A Community Based Cross-Sectional Study. Archives of Public Health. 2016;74(1):1.

45. Beka TWK, Zewditu G, Girum T. Magnitude and determinants of stunting in children underfive years of age in food surplus region of Ethiopia. The case of West Gojam Zone, Ethiopia. J Health Development. 2009;23:98-106.

46. Seb Rengma M. BK, Mondal N. Socio-economic and demographic correlates of stunting among adolescents of Assam, North-east India. Anthropol Rev. 2016;79.

47. Mandefro Asfaw MW, Mohammed Taha and Lamessa Dube. Prevalence of undernutrition and associated factors among children aged between six to fifty nine months in Bule Hora district, South Ethiopia. BMC Public Health 2015 15:41.

48. Blessing J. Akombi I, Kingsley E. Agho, John J. Hall, NidhiWali, Andre M. N. Renzaho and Dafna Merom Stunting, Wasting and Underweight in SubSaharan Africa: A Systematic Review. International Journal of Enviromental Research and Public Health. 2017.

49. Wamani H, Astrom AN, Peterson S, Tuamwine K J. Boys are More Stunted than Girls in Sub-saharan Africa: A Meta-analysis of 16 Demographic and Health Survays. 2006.

50. Chandrashekhar T Sreeramareddy NRaMS. Association between household food access insecurity and nutritional status indicators among children aged $<5$ years in Nepal: results from a national, cross-sectional household survey. Public Health Nutrition. 2014;18(16)(2906-2914).

51. Gilberto K MM, Rafael P-E, Gustavo V-M, Antonio AMdS. Household Food Insecurity Is Not Associated with BMl for Age or Weight for Height among Brazilian Children Aged 0-60 Months PLoS ONE 7(9):1-7. 2012.

52. Leonardo PdS DP. Relationship between Food Insecurity and Nutritional Status of Brazilian Children Under the Age of Five. Rev Bras Epidemiol. 2013; 16(4):984-94. 